\title{
Bus or Rail: An Approach to Explain the Psychological Rail Factor
}

\author{
Milena Scherer, ETH Zurich \\ Katrin Dziekan, Berlin Institute of Technology
}

\begin{abstract}
Many public transport studies have found that potential passengers consider railbased public transport to be superior to bus systems. Why is this? Two studies have been completed in Germany and Switzerland in search of explanations for this socalled psychological rail factor. In this article, these two studies are presented and discussed to introduce the schemata approach and to help identify differences of attributions towards rail- and bus-based public transport.

The research found a psychological rail factor (i.e., a preference for using rail assuming equal service conditions) of 63 percent for regional train and 75 percent for trams compared to bus services. The rail factor is highly loaded with emotional and social attributions. They account for 20-50 percent of the share in the different schemata for bus, rail, and tram.
\end{abstract}

\section{Introduction}

It is recognized that hard factors such as travel time, cost, availability of public transport services, and car ownership have a major impact when people consider the choice between using an automobile or public transport. Nevertheless, there is evidence from the literature that rail-based public transport often is considered superior to bus systems, even in cases where quantitative hard factors are equal. This attraction of passengers is known as a psychological rail factor, and it is used to express a higher attraction in terms of higher ridership of rail-based public 
transport in contrast to bus services (Axhausen et al. 2001; Megel 2001b; Ben-Akiva and Morikawa 2002; Vuchic 2005; Scherer 2010a). The existence of this rail factor is widely accepted among experts, but little evidence exists about the reasons for this phenomena.

The idea of a rail factor is consistent with statements that the image of a transport system has an impact on demand. Furthermore, research shows that transport characteristics often are misperceived (or misbelieved) and that costs are ranked less important by users making mode choice decisions than planners expect. This raises the question of how public transport characteristics are perceived and valued and which attributions are made towards different transport modes (Beale and Bonsall 2007; Guiver 2007). While many efforts have been undertaken to analyze customer attributions towards car and public transport in general, only a few studies distinguish between different public transport modes (e.g., Megel 2001a; Cain et al. 2009).

It is expected that the images of different public transport systems vary between regions since customer attributions derive from perceptions and beliefs, which are influenced by local conditions and different cultures (Scherer 2010a). Thus, in addition to investigating attributions toward public transport modes in general, it is of interest to explore these attributions against the background of different spatial areas. The two case studies presented in this article explore differences in attributions towards train, tram, and bus in Germany and Switzerland to enhance the knowledge about different images of public transport systems.

\section{Attributions to Public Transport Systems}

\section{Function of Attributions and Schemata}

In cognitive psychology, attributions are defined as ways in which people perceive and value a product or service. A combined set of attributions forms an image of the product or service. Attributions can be organized into categories to develop a schema. Schemata are organized packets of information about the world, events, or people, and they are stored in the long-term memory. Schemata describe more generally a cognitive structure of types of background knowledge that a person brings to any given context (Eysenck and Keane 2005).

These schemata are abbreviations and save cognitive resources. Since human beings need to save cognitive effort, they build up behavior routines based on schemata, stereotypes, and scripts. This makes life easier, because one does not have to 
think in depth about everyday things. Hence, analyzing cognitive structures such as schemata is important for understanding human behavior.

Understanding schemata about specific issues provide useful information how people perceive specific concepts. For further research, the question of how these schemata influence behavior becomes prominent. The next section outlines how attributions and schemata have been considered in public transport research.

\section{Literature Review of Public Transport Attributions}

Attributions to public transport are important; they form the perception of a public transport mode and, thus, the image of different public transport modes. Perception of public transport service quality and attributions of public transport have been prominent issues in transportation research, especially research that targets shifting automobile drivers towards public transport. Investigation of perception and attributions usually is based on qualitative research such as focus group discussions and semi-structured interviews.

Negative attributions towards a transit mode usually result in a poor image of this mode. This can be shown with the psychological model of barriers to train use developed by Dziekan et al. (2004). They found that barriers to train use are higher when this mode is loaded with negative attributions. It is of interest to enhance the knowledge about the quality of the attribution in order to investigate their influence on intended behavior on barriers towards behavior.

A key problem with using attributions to investigate mode choice decisions is that many studies do not distinguish between public transport modes (e.g., Wirthlin Worldwide and FJCandN 2000). However, several recent studies have made a differentiation between various bus and light rail modes. Cain et al. (2009) found that full bus rapid transit (BRT) is perceived by everyone as superior to regular bus services in the Los Angeles region. In contrast, although other high-quality bus services (non-BRT) also were highly regarded by their users, the general public's view was influenced by the same negative perceptions as regular buses. Hence, modal familiarity led to a higher acceptance of the respective transport mode.

Widell and Olsson (2002) found in their research on Stockholm's subway system that the subway had more negative attributions than other public transport systems in Stockholm. Two main reasons were found for the negative perception. First, the old subway trains were rated as too noisy since they had the worst rating of all public transport vehicles investigated. Second, the Swedish prefer daylight to underground situations for cultural reasons. 
Guiver (2007) found in a discourse analysis of focus group discussions on bus and car travel that the local buses often were seen as sub-standard when compared with bus services in other cities. Both the activated scenario and the selective attributions towards bus travel support the assumption that mode choices are being made partly on personal experiences and common cultural representations of modes. This means that planners need to consider different pre-conceived beliefs as well as ways of thinking and processing information when they design public transport systems (Beale and Bonsall 2007).

Megel (2001a) has shown that the schemata approach is an appropriate method for investigating and describing different attributions to trams/trains and buses. She developed a prototype for "rural public transport" and its subcategories "train ride" and "bus ride" based on corresponding attributions.

With regard to different attributions to bus and light rail, light rail generally is perceived as more reliable, more comfortable, faster, and more spacious than buses. Furthermore, light rail is more often rated higher concerning intangible factors, a finding that emerges from positive attributions such as "new, enjoyable, and attractive" (Beirão and Cabral 2007).

Existing studies have shown that public transport modes are attributed with different aspects; respectively, they are rated differently by different stakeholders. These attributions are not constant over locations and times and depend on existing public transport services. Furthermore, negative or weak attributions have been found to act as barriers to a specific travel behavior. The case studies presented in this article aim to present differences in public transport modes based on the psychological concept of schemata. These schemata serve as basis for the discussion of positive and negative attributions that may stimulate or hinder certain travel behavior.

\section{Description of Case Studies}

\section{Method}

Both case studies presented here explore public transport attributions by applying a content analysis (Mayring 1993) and coding of the attributions. The starting point was the German study that comprises a psychological investigation of preferences and attributions of different regional public transport systems, bus and train, to investigate the rail factor. This work was based on structured face-to-face interviews with inhabitants in two mid-size cities in Germany. The public transport service was, in one case, bus-based and, in the other, mainly based on regional trains. 
The Swiss study developed the approach from the German study further to investigate the two common urban public transport systems bus and light rail (tram) on a nationwide basis. Therefore, data were collected with a web-based questionnaire and sent to a random sample of Swiss residents. The allocation of the participants into areas served by bus or tram was based on residential postal codes.

\section{The German Study: Face-to-Face Interviews on Regional Public Transport}

The first study to investigate the psychological rail factor was conducted in 2000 by Megel (2001a; 2001b). The research focused on the underlying reasons for preferring rail-based public transport over bus-based public transport. Why do people choose one or the other? The respondents were asked to answer the following hypothetical question:

Imagine the following hypothetical situation: To go from A to B, you may choose between a bus ride and a train ride. The travel time of 60 minutes is the same for each mode. The route, your way to the stop, the ticket price, and the service frequency would be the same. What would you choose-bus or train?

The respondents subsequently were asked why they chose one or the other public transport option to reveal the attributes in the train schemata and bus schemata. Face-to-face interviews were conducted using a semi-standardized questionnaire. Talking directly to people ensured that they really understood the question and were motivated to give as many reasons as possible for their decision on the hypothetical question. Information about gender, age, frequency of public transport use, last bus or train ride occurence, educational background, ownership of half-fare card for train travel (Bahncard 50), car availability, and income also was collected.

The face-to-face survey was conducted in the city centers and inner-city market places in two medium-size cities in Eastern Germany (Annaberg-Buchholz and Bischofswerda) by trained interviewers on normal weekdays. The locations were not close to the train station or bus stops to avoid priming effects or biases in the answers. Inhabitants older than 18 years were asked to participate in the survey. The representative sample consisted of 422 people.

\section{Preferences}

The results showed that 63 percent of the people chose the regional train in the hypothetical situation. This confirms the existence of a rail factor. Against the expectations that good bus service or bad train service have an influence on preference, no significant differences concerning the decision in favor for train were 
found between the structurally comparable regions of Annaberg-Buchholz (bus region) and Bischofswerda (train region).

A detailed analysis of the data showed that neither gender nor income had an influence on the preference for rail. However, the frequency of public transport use did have a positive influence on the rail preference: almost all heavy users (use public transport nearly every day) of the regional train service preferred train and almost all owners of a half-fare card preferred train travel. Furthermore, increasing education level showed correlations to the train preference.

The data also showed that younger people (18-24 years) have a significantly higher preference for train travel than older people (>65 years) (Megel 2002). Almost 80 percent of the younger people in the sample preferred train, while only 46 percent of the older people chose the train. A detailed analysis showed that older women are more likely to prefer the bus than older men (67\% vs. $41 \%$ ). In the bus region, significantly more non-captives (car available in the household and ownership of driver license) preferred the train over the bus (captives train preference $51 \%$ vs. non-captives train preference $68 \%$ ).

\section{Attributions}

The interviewers collected detailed information on the reasons for choosing the train or the bus option. Each person gave, on average, three explanations for their choice. Using the method of content analysis (Mayring 1993), all answers were analyzed and categorized into pre-defined subcategories of the schemata framework (see Table 1 for first attributions). Since first attributions are directly related to the "picture in mind" that one has when thinking about the preferred public transport system, they contribute best to the schemata of bus and train.

The majority of the attributes for the train choice were:

- Emotional attributions (38\%)

- Activity space (12\%)

- Contra bus arguments (7\%)

- Seats (5\%)

- Attributions to guideway (5\%)

The most important subcategories for first attributions for the bus decision were:

- Routing (23\%)

- Emotional attributions (19\%)

- Experience (13\%)

- Attributions to guideway (9\%) 
Table 1. Comparison of First Attributes to Riding Regional Train $(\mathbf{N}=\mathbf{2 6 1})$ and Riding Regional Bus ( $\mathbf{N = 1 4 6 )}$ in the Different Subcategories

\begin{tabular}{|c|c|c|c|}
\hline Category/Subcategory & Examples & $\%$ Bus & $\%$ Tram \\
\hline \multicolumn{2}{|l|}{ Emotional factors } & 43.1 & 51.7 \\
\hline Emotional attributions & Convenient, attractive, nostalgic & 18.5 & 37.5 \\
\hline Usability & Less complicated, easy to use & 0.7 & 0.4 \\
\hline Train ride in itself & Enjoy the ride & - & 1.5 \\
\hline Emotion & Like train/bus ride & 3.4 & 4.2 \\
\hline Stress/relax & More relaxed, less stressful & 0.0 & 1.1 \\
\hline Experience & Habit, familiarity, memories & 13.0 & 4.2 \\
\hline Staff & Friendly staff & 0.0 & 0.0 \\
\hline Security & Better security feelings & 4.1 & 0.0 \\
\hline Social factors & Less crowded, communicate, socializing & 2.0 & 0.4 \\
\hline Others & Ambience, flair & 1.4 & 2.3 \\
\hline \multicolumn{2}{|l|}{ Interior and design } & 9.6 & 18.8 \\
\hline Activity space & More space, ability to move around & - & 11.9 \\
\hline Seats & Higher seat comfort, more leg space & 2.7 & 5.0 \\
\hline Seat selection & Higher seat availability & - & 0.0 \\
\hline Design & Better boarding & 4.8 & 0.4 \\
\hline Others & Climate/air conditioning in vehicle & 2.1 & 1.5 \\
\hline \multicolumn{2}{|l|}{ Guideway and route } & 31.5 & 14.6 \\
\hline Routing & Density and distribution of stops & 22.6 & 2.3 \\
\hline Advantages of tracks & Dedicated right-of-way & - & 0.8 \\
\hline Attributions to guideway & Faster, on time, more reliable & 8.9 & 4.6 \\
\hline Others & Environmental reasons & & 3.8 \\
\hline \multicolumn{2}{|l|}{ Activities and possibilities } & 1.4 & 6.1 \\
\hline Activities & Reading, smoking, studying & - & 2.3 \\
\hline Luggage & Possibility to carry bicycle & 1.4 & 0.8 \\
\hline Children/family & Ability to take stroller, better for children & 0.0 & 1.5 \\
\hline Toilet & Toilet available & - & 1.1 \\
\hline Services & Restaurant/minibar & - & 0.0 \\
\hline Others & Attractive stations, openable windows & - & 0.4 \\
\hline \multicolumn{2}{|l|}{ Contra reasons } & 9.6 & 6.5 \\
\hline Contra bus & Travel sickness, density of bus stops & - & 6.5 \\
\hline Contra system rail & Remote train stations. & 4.1 & - \\
\hline $\begin{array}{l}\text { Contra train-probably not } \\
\text { system-dependent }\end{array}$ & $\begin{array}{l}\text { Bad experiences with train rides, anonymity in the } \\
\text { train }\end{array}$ & 4.1 & - \\
\hline $\begin{array}{l}\text { Contra train-not system- } \\
\text { dependent }\end{array}$ & Dirty stations, dirty vehicle interiors & 1.4 & - \\
\hline \multicolumn{2}{|l|}{ Other reasons } & 4.8 & 2.3 \\
\hline & Cheap prices & 4.8 & 2.3 \\
\hline \multicolumn{2}{|l|}{ Total } & 100.0 & 100.0 \\
\hline
\end{tabular}


All attributes for train and for bus were categorized into subcategories that derived from the schemata frames as presented in Table 1 with according percentages. In both schemata, the majority of attributions were concerned with aspects of the category emotional factors ( $52 \%$ for train and $43 \%$ for bus). For the train schema, the attributions regarding design/interior and activities/possibilities were more important than in the bus schema. Aspects of the route/line such as flexibility and availability were the major positive attributes in the bus schema.

About 7-10 percent of the first attributions account for contra reasons that are expected to strengthen ones barrier for the choice of this mode and also enforce the current preference. Interestingly, differences between contra reasons on bus and train are small. Considering the literature review where buses where found to be more often related with negative scenarios, this was not expected.

Since the respondents were asked to list all reasons for their preference, it is interesting to compare the overall picture they construct with all reasons given to that of the first attributions (see Scherer et al. 2011 for the review of all attributions).

- There is a remarkably higher share of emotional attributions for trains in first attributions (38\%) compared to the comprehensive list (18\%).

- The share of emotional attributions is also high for buses, but not to the same extent as for trains (19\% and 14\%).

- Contra bus arguments have the third-highest share of first attributions in the train schema (7\%). When considering all arguments, the share decreases to less than 5 percent.

- The ranking of bus attributions remains similar regarding first attributions and all attributions towards bus preferences. Attributions for tram preferences show a higher variation between first-mentions and all attributions.

As the first argument that one has in mind intuitively has a higher weight in the schemata concept, we conclude that the rail factor established in this study is mainly driven by emotional factors and contra reasons that form a barrier towards bus modes.

\section{The Swiss Study: Web Questionnaire to Bus and Tram}

The second case study is a Swiss survey conducted in autumn 2009 by Scherer (2010b). The study's two main objectives were first, to collect reasons and attributions for the preferences of bus and tram to be used in the subsequent investigations of perception of urban public transport, and second, to explore the situations and preferences of residents of different areas in Switzerland, including rural areas, 
conurbations, and urban areas with and without tram presence, to provide first indications of different attributions made by respondents.

Almost every municipality in Switzerland is served by public transport. In remote mountainous areas, service is mostly bus-based, but regional rail service also is possible, depending on the geographical location. Urban areas and conurbations are served by high-quality bus service and commuter rail. The four biggest conurbations - Geneva, Berne, Basle, and Zurich—also provide tram services, and Lausanne has one subway line on tires due to topographical conditions. Public transport is integrated in a tariff system, with no distinction between transport modes. This allows passengers to transfer without any obstacles between rail, bus, and tram.

The small size of the country and the high availability of public transport services allow the assumption that most of the residents have some experience with public transport in general and also with tram service in particular. According to the Swiss Federal Statistical Office (2007, p. 38), on average, every resident boards a public transport vehicle 218 times per year.

Data were collected by means of a web survey. Similar to the German study, the survey contained questions in a hypothetical setting, which required a high cognitive effort by the participants. This imagination is mainly influenced by cognitive structures (schema, prototypes, and memory representations) that are built up from the experiences, habits, attitudes, etc., of the participants. The respondents were asked to imagine two urban public transport modes (bus and tram) under exactly the same service conditions regarding timetables and availability, and then to state which mode they would prefer in the given situation. Next, they were asked to provide up to three reasons for their decision.

The questionnaire contained a combination of stated preference questions in an open and closed form. It was attached to a web-based omnibus survey provided by a market research institute (an omnibus survey is a survey where several different customers can include their questions on the same survey). This is especially convenient for a small amount of questions and has the advantage of sharing the costs for collection of socio-demographical data between customers. Due to its characteristics, an omnibus covers respondents that are online at least once a week and are between the ages of 15 and 75 years.

The universe of the study was all residents living in the German- or French-speaking areas of Switzerland. The Italian area was neglected because, in contrast to the 
other two regions, there is no tram service in this region. Finally, 515 questionnaires were included in analysis.

\section{Preferences}

The answers to the hypothetical question about the preference for bus or tram operating under same service conditions showed a clear preference for trams. A total of 385 (75\%) of all respondents preferred the tram, and 130 (25\%) chose the bus (see Figure 1).

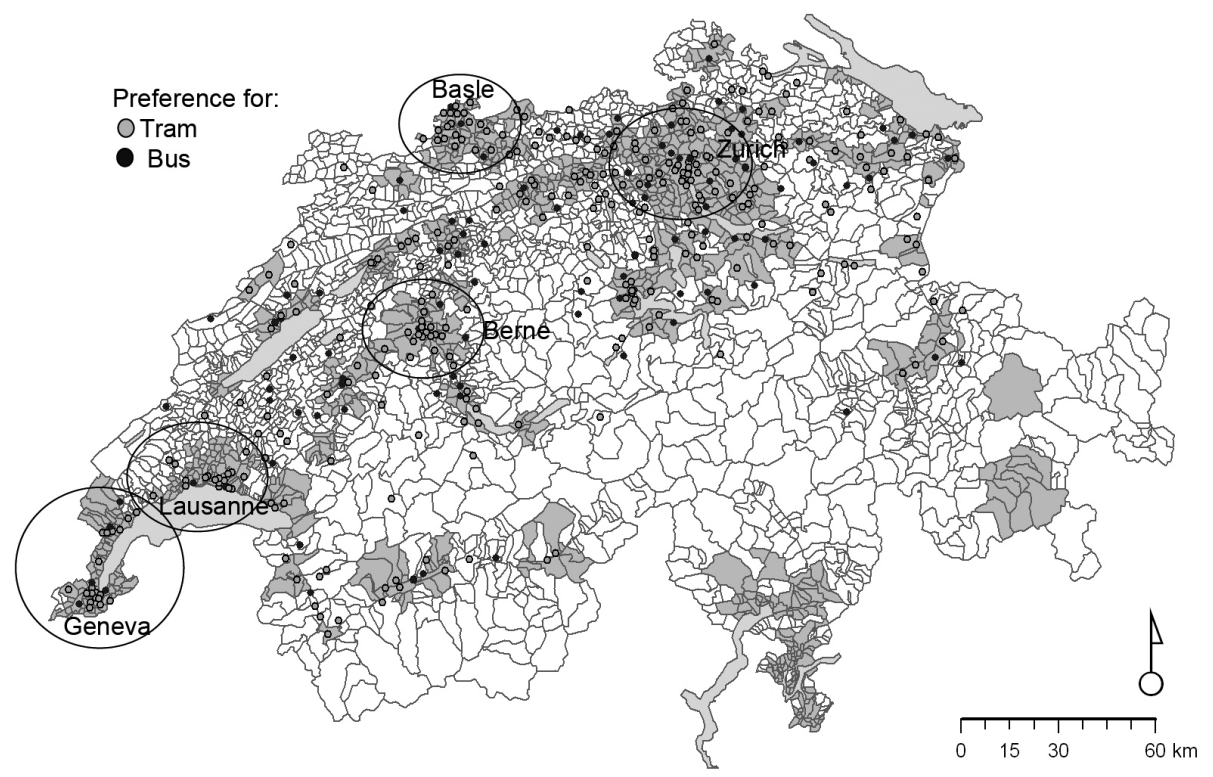

Figure 1. Spatial distribution of preferences

\section{Attributions}

The stated reasons for the preference were classified according to the key presented in Table 2. A total of 999 reasons for tram preference and 281 reasons for bus preference were collected and classified. Based on the assumption that the first answer is highly related to the "picture in mind" that one has when thinking about the preferred public transport system and to not overrate the second and third answers, only the first reasons were selected for this analysis. This means that, in total, 372 reasons for a tram preference and 132 reasons for a bus preference were analyzed (see Table 2). 
Table 2. Categorization Key and First Attributions in Swiss Study

\begin{tabular}{|c|c|c|c|}
\hline Categories/Subcategory & Examples & $\begin{array}{c}\% \\
\text { Bus }\end{array}$ & $\begin{array}{c}\% \\
\text { Tram }\end{array}$ \\
\hline \multicolumn{2}{|l|}{ Vehicle characteristics } & 37.1 & 20.0 \\
\hline Seat/space & $\begin{array}{l}\text { Spacious interior, availability of seat, more space, less } \\
\text { full, comfortable (to sit) }\end{array}$ & 30.3 & 15.1 \\
\hline Boarding & Low-floor, wider doors, easier to board & 0.8 & 2.2 \\
\hline Atmosphere & $\begin{array}{l}\text { Modern, new, air-conditioned, better ambience, } \\
\text { cleanliness, more comfort, quiet }\end{array}$ & 6.0 & 2.2 \\
\hline Sight & Overview in vehicle, better sight/windows & - & 0.5 \\
\hline \multicolumn{2}{|l|}{ Attributions of guideway } & 16.7 & 46.0 \\
\hline Reliability & Right-of-way, dedicated lane, on time, reliable & 6.1 & 29.3 \\
\hline Flexibility & No tracks/wires, flexible routing & 1.5 & - \\
\hline Ride comfort & Comfortable to ride, less shaking & 5.3 & 11.6 \\
\hline Orientation & Visibility of guideway & 3.8 & 0.5 \\
\hline Safety & Safety, fewer accidents & - & 4.6 \\
\hline \multicolumn{2}{|l|}{ Availability factors } & 11.4 & 4.8 \\
\hline Service & $\begin{array}{l}\text { Distribution of stops, timetable/frequency, opera- } \\
\text { tion hours, connections, routing, service informa- } \\
\text { tion, availability of service }\end{array}$ & 11.4 & 4.8 \\
\hline \multicolumn{2}{|l|}{ Environmental issues } & 3.0 & 16.9 \\
\hline Environmental aspects & $\begin{array}{l}\text { Environmentally friendly, no exhaust, less noisy, } \\
\text { energy consumption }\end{array}$ & 3.0 & 16.9 \\
\hline \multicolumn{2}{|l|}{ Activities during ride } & - & - \\
\hline Activities during ride & Ability to read or work during ride, bring luggage & - & - \\
\hline \multicolumn{2}{|c|}{ Emotional and social factors } & 27.3 & 11.2 \\
\hline Positive feelings & $\begin{array}{l}\text { Convenient, better, something special, easier to use, } \\
\text { ride pleasure, attractive, relaxed }\end{array}$ & 15.1 & 7.5 \\
\hline Habit/ knowledge & Habit, practice, nostalgic reasons, familiarity & 9.1 & 2.1 \\
\hline Special connection & Rail fan, Job at railway company & - & 1.3 \\
\hline Socialising & Meet other people & 2.3 & - \\
\hline Connection to area & More rural, urban feelings & 0.8 & 0.3 \\
\hline Security & Aggressive riders & - & - \\
\hline \multicolumn{2}{|l|}{ Other reasons } & 4.5 & 1.1 \\
\hline Contra reasons & I don't like the other mode & 4.5 & 1.1 \\
\hline Sickness & & - & - \\
\hline Other reasons & Costs, etc. & - & - \\
\hline \multicolumn{2}{|l|}{ Total } & 100.0 & 100.0 \\
\hline
\end{tabular}


From those who preferred using a bus, the first attributions in subcategories towards a bus were:

- Seat/space in vehicle (30\%)

- Positive feelings (15\%)

- Availability of service (11\%)

- Habit/knowledge (9\%)

The overall data then were analyzed compared to socio-economic variables to identify patterns for bus preferences. In contrast to the attributions towards a tram, as presented below, no significant impact of socio-demographic variables was detected for the bus schema.

From those who preferred using trams, the first attributions in subcategories towards a tram were:

- Reliability (29\%)

- Environmental aspects (17\%)

- Seat/space in the vehicle (15\%)

- Ride comfort (12\%)

Two variables were found to have a significant association with the attributions to tram: ownership of a public transport pass (PT-pass) and place of residence. Both PT-pass owners and non-owners ranked guideway attributions as most important, but PT-pass owners ranked vehicle attributions as well as emotional and social attributions higher than environmental benefits, while non-PT-pass owners ranked environmental benefits second to guideway situation.

In terms of place of residence, the ranking of most important attributions for inhabitants of rural areas are guideway, environmental issues, and emotional factors, in contrast to people living in tram cities where vehicle attributions were mentioned far more often. The rank order of attributions of inhabitants of the three spatial classes (rural, conurbation without trams, conurbation with trams) follows assumed traffic concerns or traffic problems usually encountered in these locations.

Emotional and social factors play a less prominent role in attributions than expected from the German study. One third of the arguments for a bus preference concerned the seat/space situation in vehicles, and one third of the arguments for a tram preference are based on guideway characteristics related to higher reliability. Overall, a tram gets a higher share of rational reasons for its preference mentioned as first attribution than a bus. One third of the first attributions to a bus are based on emotional and social factors and contra reasons to a tram. Preferences in this 
study show more rational reasons compared to those in the German study. One explanation might be that people had time to reflect their attributions since they had to write them down. In contrast, in the German study, the participants where asked to explain their choice in personal interviews. This methodological difference may lead to a higher share of rational reasons.

\section{Schemata of Bus, Tram and Train}

\section{Recoding of Answers}

Two persons recoded the attributions for bus and regional train from the German study independently according to the categorization key in Table 2 . The recoded dataset serves as a basis for comparison of attributions towards urban and regional bus and tram and regional train. The results from the recoded dataset differ marginally from the original studies due to exclusion of attributions that contradict the hypothetical situation of equal public transport services.

General caution has to be exercised when comparing the results of both case studies, because these studies were completed in different times (2000 and 2009) and different geographical areas with variances in public transport service levels. Since public transport service has changed only marginally in the German study areas over the last 10 years, the effect of different time horizons on level of service aspects can be neglected.

The main socio-demographic difference between the two datasets is ownership of a public transport pass (German study $=7.5 \%$, Swiss study $=43 \%$ ). Distributions of other variables such as gender, age, household size, and number of cars per household are similar across both datasets.

\section{Schemata}

Figure 2 shows the resulting schemata for regional bus, regional train, urban bus, and tram based on recoded first attributions mentioned in the surveys. It can be seen that each schema is loaded differently with the defined categories from the classification key in Table 2-in other words, the schema for each mode contains different numbers of categories of attributions, e.g., regional trains includes the category "activities during ride" but none of the other modes do. 


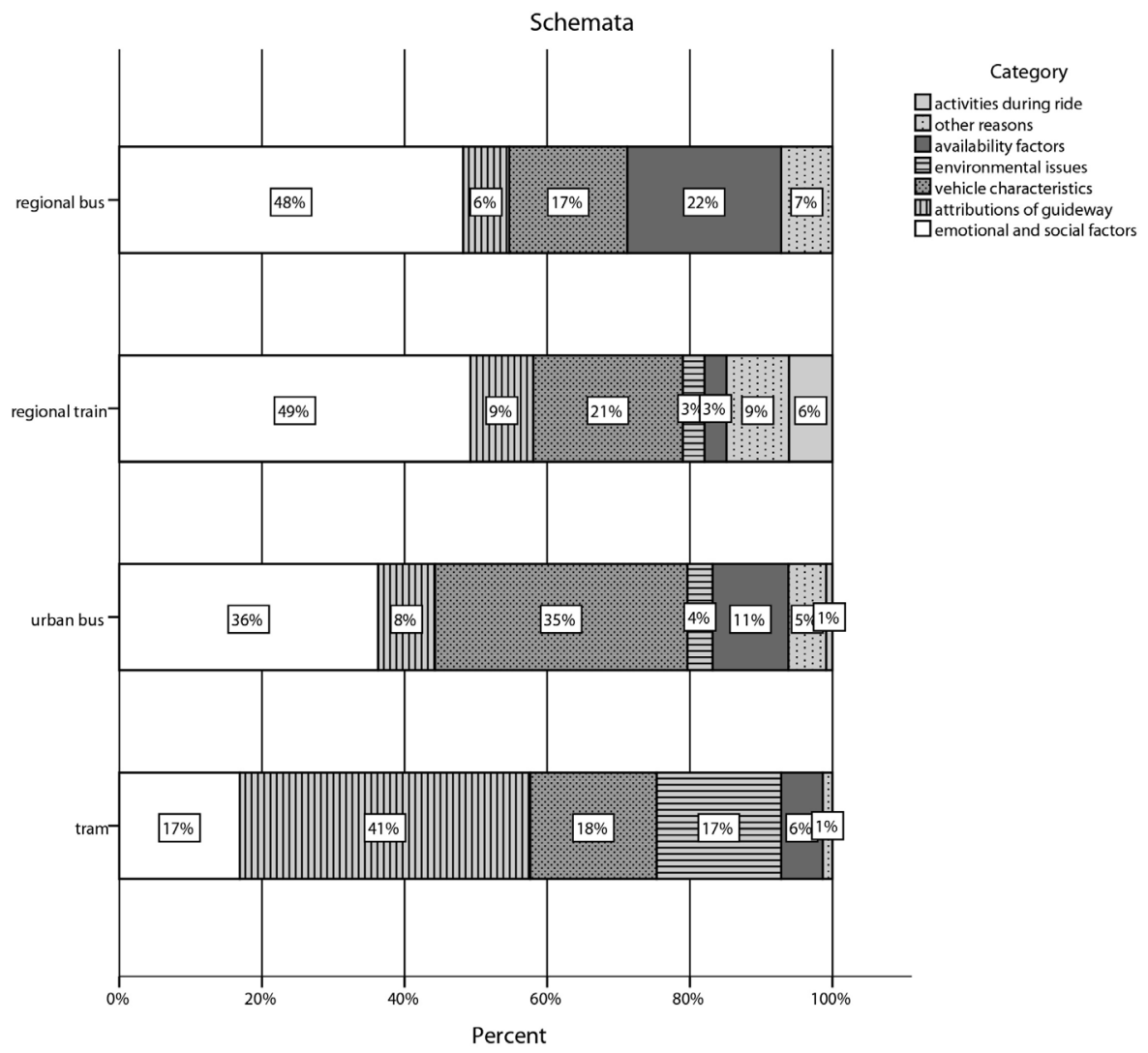

Figure 2. Schemata for tram, train, urban and regional bus

Considering the resulting schemata, regional bus and regional train are highly loaded with emotional attributions. Almost 50 percent of the first attributions towards these transport modes fall within this category. The share of emotional and social factors is also high in the schema of urban buses (36\%). Compared to that, the tram schema is less loaded with emotional factors (17\%).

Regarding regional transportation, it can be seen that reasons for people preferring a bus include a higher availability of bus service compared to train service. In contrast, a train is more suitable for conducting activities during a ride. This reflects the local situation in the case study areas.

In urban areas, a tram is heavily linked to positive guideway attributions and has strong environmental-friendly attributions. These attributions correspond with congested situations and emerging environmental discussions in cities. 
Since schemata support cognitive shortcuts and finally influence people's behavior, it is interesting to establish that about 20-50 percent of the schemata for public transport modes are emotionally driven. According to the schema theory, the influence of positive feelings towards a mode, habit and knowledge, and barriers towards other modes are expected to have a significant effect on travel behavior.

\section{Discussion}

In both studies, a high preference for rail-based systems was found. In the underlying hypothetical situations where public transport opportunities are equal, a rail factor definitely exists for the case study areas. However, since the questionnaires did not allow for undecided respondents, their role should be mentioned as well. These respondents could have a higher tendency for choosing tram/rail due to an unconscious rail preference (which, of course, further supports the existence of a rail factor). Assuming that undecided respondents may tend to favor tram/rail when asked in a survey, an even higher rail preference would be the result.

The schemata approach is based on the first (intuitive) response mentioned for the respective preference. An answer is expected to be more intuitive when a less cognitive effort is needed to give a reason for preference. Hence, the personal interviews conducted in Germany meet this condition better than the web-based questionnaire in the Swiss study, because filling out a questionnaire requires more time and allows reflecting on the answer. Thus, it is expected that the schemata built up from reasons mentioned in the German study correspond higher with the real picture in mind than the schemata constructed with reasons from the Swiss study. As a consequence, emotional and social factors tend to be underestimated in the schemata for urban bus and tram.

As first attributions show a higher share of emotional and social factors than the comprehensive set of attributions, we conclude that they have a higher weight in a schemata and also a higher weight for certain behavior. Furthermore, emotional and social aspects also include attributions from people who were unable to define their reason for preference in words. Hence, the inability to express what someone likes about a public transport mode is expected to have a high share in this category since the respondents in this situation tend to give general answers such as "better," "I like," etc., although they might really be affected by other attributions (e.g., they might have meant that one mode is more reliable). 
In congested areas with high demand, the main travel concerns are reliability (attributions of guideway) and space in the vehicle. Reliability is attributed to trams with their dedicated rights-of-way and far less to buses. On the other hand, buses are expected to have higher seat availability than trams. This category (vehicle characteristics) encompasses, on the one hand, aspects such as vehicle size and capacity (which favor trams) but, on the other hand, expected crowding conditions and, hence, buses are seen as less crowded and thus providing more space. This is especially interesting since the people choosing bus seem to expect that more public transport customers are riding trams. This also reflects a hidden rail factor in urban areas.

The category availability factors tend to have a higher impact in regional areas where public transport service is less dense. In these cases, a bus is expected to be more effective to meet availability needs. This reflects differences in routing and stop-distributions between regional train and regional bus services. This category especially can be influenced by cultural differences, since availability of regional public transport service is higher in Switzerland than in Germany.

In the category of environmental issues, the higher share attributed to urban public transport can be influenced by the time when the study was conducted. The climate debate was far less prominent in 2000 (when the German study was completed) than in 2009 (when the Swiss study was completed). Nevertheless, the data show the unsurprising tendency that rail-based public transport is considered to be more environmentally-friendly than buses.

\section{Conclusions}

The results support the assumption of a hypothetical psychological rail factor. Derived from the psychological approach of schemata, 20-50 percent of the explanation for the psychological rail factor is based on emotional and social aspects such as positive feelings and habits. Schemata are influenced by local conditions and, as a consequence, they cannot be generalized and applied to different regions properly without considering different cultural backgrounds.

Our findings underline the conclusion in Cain et al. (2009) that specific locations influence the image of a public transport system. Furthermore, similar to Cain et al. (2009), the results show that familiarity with a certain mode tends to influence the preference. The ratio of preferences for trams is lower in rural regions compared to tram cities in the Swiss study. Additionally, the German study found a higher 
preference for train by owners of specific travel cards. With regard to the findings of Beirão and Cabral (2007), the same attributions have been found as relevant except for the space in the vehicle.

In contrast to common mode choice models that are mostly based on hard factors, this research was based on the concept that attributions towards a public transport system form the basis for system perception and image. Attributions can be combined into categories that form schemata for different modes. Since schemata and similar routines are used as cognitive shortcuts, they affect human behavior. However, further research is needed to investigate the specific relationship between public transport schemata and travel behavior, e.g., to contribute to mode choice models. Schemata give a valuable insight in irrational reasons for mode choice that are mostly excluded in common mode choice models.

The presented studies support the conclusion that how people think and talk about public transport modes reflects the schemata of public transport modes. Schemata are a useful background for helping design public transport systems. For example, thinking of barriers toward public transport use in general or buses in particular, the schema shows that implementing small individual measures to improve bus service are not likely to be effective since the bus schema is highly loaded with emotional factors, based on experiences and habits. Considering the findings of Guiver (2007) concerning negative scenarios and the importance of contra arguments combined with the psychological model by Dziekan et al. (2004), we find it questionable whether single improvements targeting only one attribution can lead to higher demand. Overcoming one negative attribution is not simply a matter of creating a more positive image for a public transport mode.

Our findings give an overview of the relevance of rather irrational reasons related to the decision making of public transport customers. For practitioners, it is important to know more about the image and schemata of the different PT modes. This allows for specific improvements of public transport services by appropriate consideration of these aspects, which account for 20-50 percent of the schemata.

\section{References}

Axhausen, K. W., T. Haupt, B. Fell, and U. Heidl. 2001. Searching for the rail bonus: Results from a panel SP/RP study. European Journal of Transport and Infrastructure Research, 1(4): 353-369. 
Beale, J. R., and P. W. Bonsall. 2007. Marketing in the bus industry: A psychological interpretation of some attitudinal and behavioural outcomes. Transportation Research Part F, 10: 271-287.

Beirão, G., and J.A. Sarsfield Cabral. 2007. Understanding attitudes towards public transport and private car: A qualitative study. Transport Policy 14: 478-489.

Ben-Akiva, M., and T. Morikawa. 2002. Comparing ridership attraction of rail and bus. Transport Policy 2: 107-116.

Cain, A., J. Flynn, M. McCourt, and T. Reyes. 2009. Quantifying the importance of image and perception to bus rapid transit. Report FTA-FL-26-7109.2009.3, U.S. Department of Transportation, Washington D.C.

Dziekan, K., B. Schlag, and I. Jünger. 2004. Barrieren der Bahnnutzung-Mobilitätshemmnisse und Mobilitätsbedürfnisse (Barriers of using a train-Mobility barriers and mobility needs). In Schlag, B., Verkehrspsychologie: Mobilität Sicherheit - Fahrerassistenz. Pabst Science Publishers, Lengerich: 63-81.

Eysenck, M. W., and M. T. Keane. 2005. Cognitive Psychology: A Student Handbook. East Sussex, Psychology Press Ltd.

Guiver, J.W. 2007. Modal talk: Discourse analysis of how people talk about bus and car travel. Transportation Research Part A 41: 233-248.

Mayring, P. 1993. Einführung in die qualitative Sozialforschung: Eine Anleitung zu qualitativem Denken (2nd Edition). Weinheim: PVU.

Megel, K. 2002. Bus oder Bahn? Präferenzen älterer Menschen im Regionalverkehr. Mobilität und gesellschaftliche Partizipation im Alter. B. Schlag and K. Megel, Stuttgart, Kohlhammer W. Band 230 der Schriftenreihe des Bundesministeriums für Familie, Senioren, Frauen und Jugend: 258-270.

Megel, K. 2001a. Bus oder Bahn? Psychologische Untersuchung der Schemata und Präferenzen im Regionalverkehr. Master's thesis, Traffic and Transportation Psychology, Dresden, Technical University.

Megel, K. 2001b. Schienenbonus: Nur ein Mythos? Bus oder Bahn im Regionalverkehr-Schemata und Präferenzen. Der Nahverkehr 19 (6): 20-23.

Scherer, M. 2010a. Is light rail more attractive to users than bus transit? Arguments based on cognition and rational choice. Transportation Research Record 2144: 11-19. 
Scherer, M. 2010b. Tram or bus: Who prefers what and why? Stated reasons for preference. Working paper, Institute for Transport Planning and Systems (IVT), ETH Zurich, Zurich.

Scherer, M., K. Dziekan, and C. Ahrend. 2011. Exploring the rail factor with schemata of bus and rail: two studies from Germany and Switzerland. Paper presented at the 90th Annual Meeting of the Transportation Research Board, Washington D.C., January 2011.

Swiss Federal Statistical Office (BfS) and Swiss Federal Office for Spatial development (ARE). 2007. Swiss microcensus on travel behavior (Mobilität in der Schweiz - Ergebnisse des Mikrozensus 2005 zum Verkehrsverhalten). Neuchatel, Berne.

Vuchic, V. 2005. Urban Public Transport-Operations, Planning and Economics. New York: John Wiley and Sons.

Widell, J., and C. Olsson. 2002. Identifying passengers different preferences of rail and bus services. Project Report. Transek, Stockholm.

Wirthlin Worldwide and FJCandN. 2000. Enhancing the visibility and image of public transport in the United States and Canada. TCRP Report 63, Transportation Research Board of the National Academies, Washington, D.C.

\section{About the Authors}

MiLenA SCHERER (scherer@ivt.baug.ethz.ch) is a doctoral student and research assistant at the Institute for Transport Planning and Systems (IVT) at the Swiss Federal Institute of Technology (ETH) in Zurich. She has a master's degree in civil engineering with specialization in transport engineering and transport planning. Her doctoral thesis focuses on behavioral differences caused by various public transport modes.

Katrin Dziekan (born Megel) (katrin.dziekan@tu-berlin.de) is a senior researcher at the Berlin Institute of Technology, at the chair of Integrated Transport Planning. She received her Ph.D. from the Department of Transport and Logistics at Royal Institute of Technology in Stockholm/Sweden. Her main research fields are user perspective in public transport and evaluation of transit and transportrelated measures. 